\title{
AS BRINCADEIRAS REALIZADAS POR CRIANÇAS NAS PRAÇAS DA CIDADE DE PATOS-PB
}

Recebido em: 27/07/2019

Aprovado em: 22/01/2020

Licença: @) (1) @

\author{
Alana Simões Bezerra ${ }^{1}$ \\ Diogo Peixoto Medeiros ${ }^{2}$ \\ Centro Universitário de Patos (UNIFIP) \\ Patos - PB - Brasil
}

RESUMO: A brincadeira é de fundamental importância para o desenvolvimento infantil na medida em que a criança pode transformar e produzir novos significados. Esta pesquisa tem como objetivo realizar um levantamento das brincadeiras que são realizadas pelas crianças nas praças da cidade de Patos-PB, assim como verificar se elas são de caráter tradicional. É uma pesquisa de campo, tendo como objetivo compreender e explicar o problema do estudo. Durante a coleta dos dados, foram observadas as seguintes brincadeiras: o futebol (travinha, dois toques), esconde-esconde, pega-pega, toca-ajuda, bola de gude e taco, onde o futebol foi a que mais se repetiu. Crianças do sexo masculino foram as mais encontradas nas brincadeiras. Pode-se concluir que se tem realizado brincadeiras tradicionais, sendo estas catalogadas, também se percebe que elas preferem os finais de semana para brincar nas praças e no horário noturno.

PALAVRAS-CHAVE: Jogos e Brinquedos. Atividades de Lazer. Criança.

\section{THE GAMES PLAYED BY CHILDREN IN THE SQUARES OF THE CITY OF PATOS-PB}

ABSTRACT: Play is of fundamental importance for child development insofar as can transform and produce new meanings. This research aims to perform a survey of the games that are performed by the children in the squares of the city of Patos-PB, as well as verify if they are of a traditional character. It is a field research, because we will observe the facts and phenomena exactly as it happens in the real, based on a consistent theoretical foundation, with the objective of understanding and explaining the problem of this research. During the research, the following games were observed: football (two touches), hide and seek, pick-up, touch-aid, marbles and clubs, where soccer was the most repeated. Male children were the most found in the games. We can also conclude that children prefer the weekends to play in the squares and at night time.

KEYWORDS: Play and Playthings. Leisure Activities. Child.

\footnotetext{
${ }^{1}$ Mestre pelo Programa de Pós-graduação em Ciências das Religiões - UFPB. Graduada em Licenciatura Plena em Educação Física - UFPB, Especialista em fisiologia do exercício - FIP, Especialista em Metodologias Ativas da Aprendizagem - UNIFIP. Professora do curso de Bacharelado em Educação Física do Centro Universitário de Patos - UNIFIP.

${ }^{2}$ Graduado em Educação Física Pelas Faculdades Integradas de Patos - FIP.
} 


\section{Introdução}

O brincar é uma das atividades mais importantes no desenvolvimento da criança. Seja ela de que tipo for, é um meio cultural de a criança expressar-se e também a oportunidade de mostrar seus sentimentos e fantasias. Crianças que brincam, demonstram ter saúde emocional e desenvolvem a capacidade de criatividade (KISHIMOTO, 2002).

Quando a criança brinca, ela entra num mundo de faz-de-conta, num mundo onde tudo pode acontecer. Tem a permissão para imaginar ser quem não é, estar em lugares e até mesmo planetas diferentes, satisfazer seus desejos, ilusoriamente, viver o inesperado e divertir-se. Desta forma, a brincadeira torna-se um cenário imaginário sem censura, tudo tem vida, fala e tem vontade própria. É nesse mundo, que coloca seu corpo em cena, como representante de papeis e vive personagens de todos os tipos como médico, bombeiro, professor, pai, mãe. A criança constrói representações e encena versões, a partir de suas experiências vividas (ALVES; SOMMERHALDER, 2006).

A brincadeira é de fundamental relevância para o desenvolvimento infantil na medida em que a criança pode transformar e produzir novos significados. Em situações dela bem pequena, bastante estimulada, é possível observar que rompe com a relação de subordinação ao objeto, atribuindo-lhe um novo significado, o que expressa seu caráter ativo, no curso de seu próprio desenvolvimento (WENETZ, 2013).

A brincadeira é um processo de relações culturais. Quando brinca, a criança manipula as imagens, as significações simbólicas que estão imbricadas na impregnação cultural a que está submetida e não apenas desenvolve comportamentos que são os prescritos pela cultura e subcultura. Sendo assim a criança passa a ter acesso a um repertório cultural próprio de uma esfera da sociedade (PIMENTEL, 2015).

Para Pinto (2005) os brinquedos podem ter pelo menos duas definições, ou é aquilo que é usado como suporte durante a brincadeira ou é uma representação social que 
é dada a um objeto industrializado ou artesanal, podendo ser ou não usados numa situação de brincadeira, conservando seu caráter de brinquedo. Desta forma, os brinquedos são um meio por onde as crianças aprendem os significados da interação social.

Kishimoto (2002) enumera outras vantagens: A criança toma iniciativas, já que essas brincadeiras não têm regras rígidas. A invenção de mudanças estimula a criatividade. As brincadeiras de rua favorecem para as crianças um contato com a cultura da sua comunidade e contribui no seu desenvolvimento motor, criativo, na sua imaginação e socialização, pois nesses tipos de brincadeiras as regras são feitas pelas próprias crianças e são flexíveis, as mesmas pode criar e modificar de acordo com sua vontade e não é preciso utilizar de muitos equipamentos para que a brincadeira possa ser realizada.

No universo da rua, as brincadeiras são vividas pelas crianças de forma constante e dinâmica, incluindo brincadeiras no quintal, na garagem ou terraço de casa. A rua, espaço tido como perdido para as brincadeiras e crianças em muitos bairros, conserva-se, nesse caso, como espaço de sociabilidade infantil. A predileção pelo brincar na rua demonstra o poder das brincadeiras tradicionais infantis, perpetuadas pela apropriação do espaço coletivo e pela oralidade (CUNHA, 2004).

Assim, no século $\mathrm{XX}$ foram criadas as praças e os parques públicos como alternativa de lazer e locais de brincadeira (OLIVEIRA, 2004). Atualmente não são considerados seguros, pois nem sempre obedecem às normas de segurança quanto à instalação e manutenção dos equipamentos e, por vezes, são utilizadas para fins ilícitos (HARADA; PEDREIRA; ANDREOTI, 2003).

Através das brincadeiras nas ruas e nas praças, as crianças formam redes de sociabilidade, cujos participantes podem ser parentes, vizinhos e colegas de escola. E, 
como os adultos, estabelecem um círculo para realizar as brincadeiras dos mais próximos, dos mais amigos e que acabam por ser os mais assíduos nesse espaço (WENETZ, 2013).

Assim, para Macedo e Robba (2002), as praças também podem ser espaços onde as pessoas se reúnem para fins comerciais, políticos, sociais, e também, religiosos. Bem como, desenvolver atividade de entretenimento. As crianças aproveitam as praças para realizar brincadeiras e fazer amizade umas com as outras.

Diante do exposto, este estudo fez um resgate e um catálogo das brincadeiras que ainda são realizadas pelas crianças nas praças da cidade de Patos-PB. Tendo em vista que, alguns fatores na atualidade estão influenciando o desaparecimento de algumas brincadeiras, tais como: o aumento da violência, a falta de espaços, os jogos eletrônicos (jogos em tablets, computadores, vídeo games, etc.), o fato de morar em apartamentos, dentre outras características que tem feito as crianças esquecerem o quão importante é a brincadeira para seu crescimento e desenvolvimento, bem como, a manutenção históricocultural. A presente pesquisa tem como objetivo realizar um levantamento das brincadeiras que são realizadas pelas crianças nas praças da cidade de Patos-PB.

\section{Material e Métodos}

Trata-se de uma pesquisa direta, de campo por meio de observação e de abordagem qualitativa. Os sujeitos investigados foram 25 crianças entre 6 e 12 anos de idade que estavam realizando brincadeiras nas praças revitalizadas da cidade de PatosPB. As praças observadas foram: Praça Francisco de Morais Guedes no bairro Bivar Olinto, Praça Joaquim Leitão de Araújo no bairro Jardim Queiroz, Praça Jordivan da Costa Lucena no bairro Jatobá, Praça José Joaquim no bairro Liberdade e Praça Gilberto da Silva Oliveira no bairro Noé Trajano. 
Todas as praças passaram por reformas e possuem equipamentos das academias de saúde, quadras de esportes e playgrounds. A seleção da amostra é não probabilística intencional, pois se oportunizou a participação de todas as crianças que estavam brincando nas praças.

Como instrumentos da pesquisa utilizou-se um protocolo de observação, construído pelos responsáveis da pesquisa com 5 itens contendo informações sobre: nome da praça, bairro, nome e descrição da brincadeira e gênero dos participantes. Este ficava em posse do pesquisador para que ele pudesse fazer as anotações acerca das brincadeiras que estavam sendo realizadas pelas crianças nas praças.

Assim, para auxiliar a coleta de dados foi utilizada a técnica de observação, este é um método que consiste na utilização de uma ficha de observação com a finalidade de que o pesquisador possa ver, perceber e registrar informações sobre determinada variável (MARTINS JÚNIOR, 2015). Existem diferentes tipos de técnicas de observação que propõe situações possíveis para o pesquisador, o participante-total, o participante-comoobservador, o observador-como-participante e o observador-total (MINAYO; COSTA, 2019).

No caso deste estudo, realizou-se por meio do observador-total, o qual o observador não se envolve com a vida de seus interlocutores, ou seja, não há interação com o grupo pesquisado (MINAYO; COSTA, 2019).

Durante as observações utilizou-se câmera fotográfica móvel, para fotografar e catalogar as brincadeiras que estavam sendo realizadas pelas crianças nas praças da cidade de Patos-PB. Com o protocolo de observação, o pesquisador identificou junto das crianças as brincadeiras e as catalogou. As observações foram realizadas em 1 mês, cada praça era visitada pelo pesquisador 2 vezes. 
Primeiramente o pesquisador ao chegar às praças e identificar as crianças que estavam brincando, explicava a pesquisa, colhia as assinaturas dos responsáveis no Termo de Consentimento Livre e Esclarecido, bem como, a assinatura da criança no Termo de Assentimento Livre e Esclarecido. Após a liberação dos responsáveis e das crianças, o pesquisador fotografava as brincadeiras, à medida que anotava as informações no protocolo de observação sobre o que estava sendo realizado nas praças.

O estudo segue a resolução 196/96 do Conselho Nacional de Saúde, a pesquisa foi submetida e aprovada pelo Comitê de Ética em Pesquisa das Faculdades Integradas de Patos - FIP, tem CAEE: 56937016.1.0000.5181.

O trabalho de análise das observações aconteceu por meio de etapas, conforme técnica proposta por Minayo e Costa (2019): a primeira é a de ordenação e organização do material: 1) a organização de textos da literatura para a discussão dos dados, 2) organização do material observado, que está contido na ficha de observação.

A segunda etapa, o momento da categorização, busca das unidades de sentido: nesse instante os pesquisadores fizeram uma leitura do material, organizaram e fizeram uma reclassificação, dando ênfase às estruturas mais relevantes. É um momento classificatório, onde se busca o significado das informações coletas.

E por fim, a interpretação da segunda ordem: os pesquisadores fizeram um diálogo com a literatura para relacionar os dados encontrados no estudo com outras pesquisas existentes sobre praças e os locais onde as crianças brincam e suas brincadeiras. 


\section{Resultados e Discussão}

Foram observadas 5 praças, onde todas elas passaram por um processo de revitalização nos últimos anos (2013-2017), favorecendo assim o uso por parte das crianças para que possam desenvolver suas brincadeiras em um espaço adequado e seguro. As praças observadas foram as seguintes: Praça Francisco de Morais Guedes no bairro Bivar Olinto, Praça Joaquim Leitão de Araújo no bairro Jardim Queiroz, Praça Jordivan da Costa Lucena no bairro Jatobá, Praça José Joaquim no bairro Liberdade e Praça Gilberto da Silva Oliveira no bairro Noé Trajano. O mapa a seguir (Figura 1) mostra a localização geográfica das praças, que estão sinalizadas com marcadores na cor vermelha.

A quantidade de praças observadas tem grande significância para o estudo, tendo em vista que, apenas as mencionadas acima haviam sido revitalizadas no período da coleta dos dados, as demais praças da cidade ainda estavam no processo de reforma.

\section{Figura 1: Mapa da localização das praças investigadas da cidade de Patos-PB.}

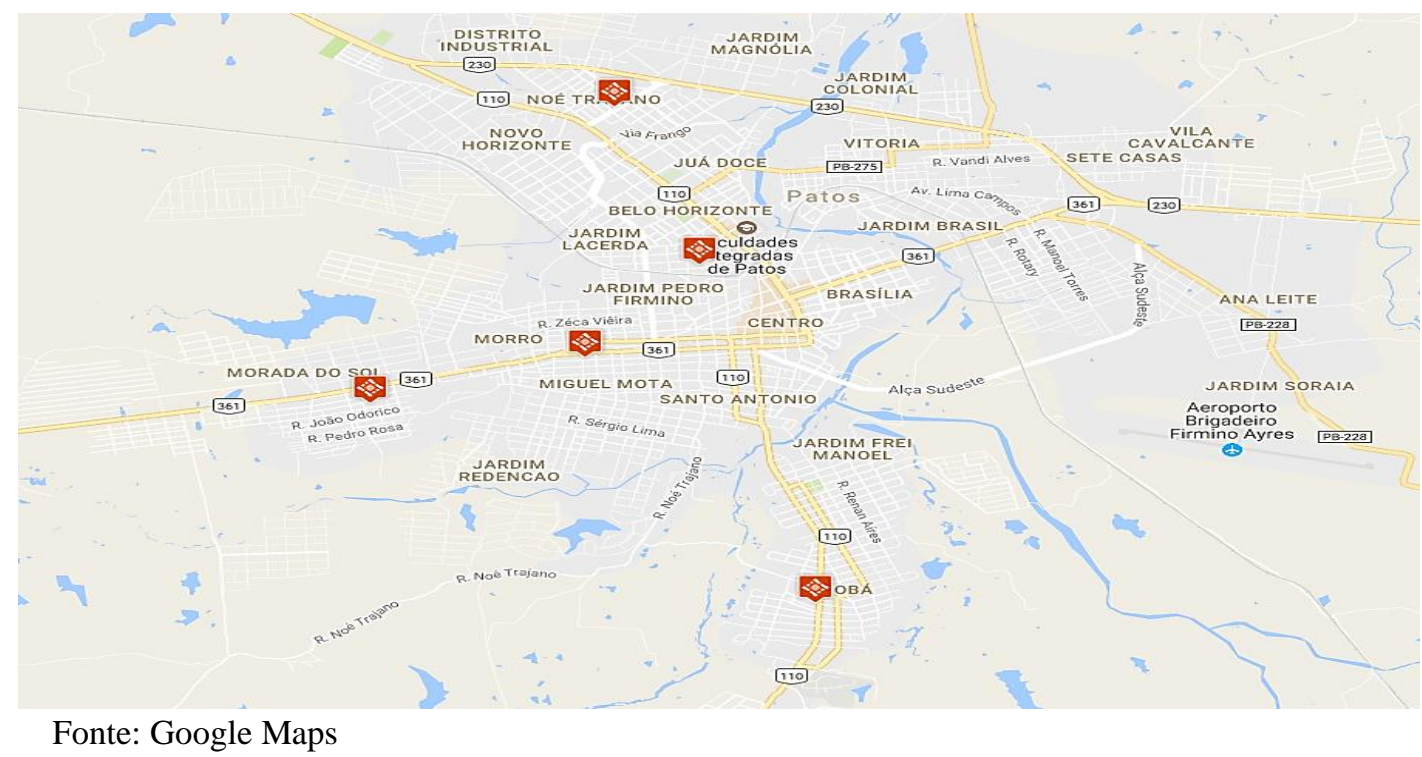

A praça é definida, como um espaço público urbano, destituído de edificações, ambiente que propicia convivência social e recreação para os seus usuários (VIERO; 
BARBOSA FILHO, 2009). Harder (2002) afirma que as praças são áreas verdes que tem entre $100 \mathrm{~m}^{2}$ e 10 hectares, mas não se pode estabelecer um padrão com relação ao tamanho sem antes conhecer o seu entorno. Macedo e Robba (2002) afirmam que as praças são espaços abertos, públicos destinados ao lazer e ao convívio da população.

Atualmente as praças da cidade de Patos-PB estão sendo revitalizadas, são espaços novos, mais verdes para a população aproveitar melhor esses ambientes para a prática de atividades físicas nas academias a céu aberto, ou para realizar jogos nas quadras esportivas, e brincar nos vários espaços. Muitas estão recebendo calçamento com acessibilidade, para que todos possam usufruir. Também são organizados os jardins, colocando bancos e mesas de concreto para melhor acolher a sociedade.

Durante a pesquisa, foram observadas várias brincadeiras. E em todas as praças havia recorrência delas. Em algumas praças as crianças estavam desenvolvendo brincadeiras nos aparelhos disponíveis para ginástica (academia da saúde), mas esse fator não era preponderante, permanecendo apenas o levantamento da prática das brincadeiras tradicionais. Identificaram-se no levantamento realizado as seguintes brincadeiras: Taco ou rebatida, pega-pega, travinha, dois toques, toca ajuda, bola de gude e esconde-esconde, abaixo estão as descrições de como elas são brincadas pelas crianças.

A seguir estão descritas as brincadeiras que estavam sendo realizadas pelas crianças nas praças:

\section{Taco ou Rebatida}

A brincadeira de Taco, também chamada de rebatida em algumas regiões se desenvolve utilizando-se 4 participantes, uma bolinha, geralmente de tênis ou uma bola pequena feita de borracha, dois tacos, geralmente feitos de madeira, podendo ser cabos de vassoura ou pedaços de pau improvisados e duas garrafas PET ou duas pedras que servem como base. 
Uma dupla começa com os tacos, que são os rebatedores e a outra dupla com a bolinha, que são os lançadores. Os lançadores irão tentar derrubar a base do time adversário, que pode ser a garrafa ou a pedra. Se o rebatedor acertar a bola, o lançador da base oposta deve correr para pegá-la. Enquanto o lançador não recupera a bola, os rebatedores correm em direção ao outro, alternando entre as bases, tocando seus tacos, fazendo com que cada batida caracterize um ponto para a dupla. Quando o lançador pega a bolinha, ele pode arremessá-la para o seu companheiro ou se algum rebatedor estiver fora da base, ele pode arremessar em direção à base, e se acertar a garrafa ou a pedra, os rebatedores passam a ser lançadores e os lançadores passam a ser rebatedores. O jogo termina quando a dupla que estiver na posição de rebatedores atingirem 10 pontos.

Percebeu-se durante as observações que nesta brincadeira houve uma predominância do gênero masculino.

\section{Pega-Pega ou Toca}

Na brincadeira de pega-pega, o número de crianças participantes é indefinido, mas geralmente varia entre 5 a 10 participantes. As crianças se reúnem e em uma breve discussão escolhem quem começa a brincadeira sendo o pegador. A brincadeira tem como objetivo principal fazer com que o pegador corra atrás das demais crianças com o objetivo de tocá-las e ao fazer isso, a criança é excluída da brincadeira ou passa a ser o novo pegador. A brincadeira não tem limite de duração, sendo encerrada quando as crianças bem entenderem, geralmente quando já estão fisicamente cansadas.

É um jogo de perseguição em que um, ou mais de um pegador busca pegar os fugitivos tocando-os. Estes, por sua vez, objetivam não serem apanhados. Há inúmeras variações que estabelecem os diferentes modos de perseguir e de fugir. Em todos há a 
presença do toque, quem for tocado, automaticamente vira o pegador ou vira gelo, a criança deve ficar parada no lugar onde foi capturado.

Nesta brincadeira, foi observado que a brincadeira estava sendo realizada por ambos os gêneros.

\section{Pega-ajuda ou toca-ajuda}

A brincadeira de pega ajuda é uma variação da brincadeira do pega-pega, relatada acima. As crianças se reúnem em grandes grupos, geralmente de 8 até 12. Elas se reúnem para decidir quem será o primeiro pegador. As demais crianças correm, a fim de despistar o pegador e não ser pego por ele. Se o pegador encostar-se a alguém, a criança tocada passará a ajudá-lo a pegar as demais. Todo o espaço da praça era utilizado, sem restrições. A brincadeira acaba quando todas as crianças são pegas. A última criança da brincadeira que for pega é a vencedora.

Ambos os gêneros foram observados praticando essa brincadeira.

\section{Esconde-Esconde}

A brincadeira de esconde-esconde ou pique-esconde, também é uma variação da brincadeira do pega-pega, é realizada com um número variado de crianças, geralmente entre 4 e 8 participantes. A brincadeira se inicia quando os participantes elegem uma pessoa para ser o contador. Esse, de olhos fechados, inicia uma contagem, até um determinado número, enquanto o restante das crianças se esconde. Ao final da contagem, o contador irá procurar as crianças que estão escondidas. Se o contador encontrar alguém, tem que correr em direção ao local em que foi feita a contagem e bater com a mão antes do outro, para que essa criança não se salve, fazendo com que a criança que estava escondida seja pega, e assim a próxima a contar. As crianças que conseguem chegar ao 
local da contagem antes do contador, são salvas e irão se esconder novamente na próxima rodada.

$\mathrm{Na}$ brincadeira de esconde-esconde ambos os gêneros foram encontrados brincando. Porém havia um maior número de meninas.

\section{Travinha}

A brincadeira travinha é uma variação do tradicional futebol. As crianças se dividem em dois times, na maioria das vezes 2 ou 3 em cada equipe. O jogo pode desenvolver-se na areia ou no chão de cimento, desde que haja um espaço amplo. A bola usada não precisa ser necessariamente uma específica do futebol, podendo ser também utilizadas bolas de outras modalidades. As traves são feitas apenas com dois objetos, pedaços de pau enterrados na areia, garrafas PET, pedras ou até as próprias sandálias das crianças. Forma-se então uma pequena trave, o que explica a origem do nome da brincadeira. O jogo se desenvolve de forma semelhante ao do futebol, onde as duas equipes se enfrentam com o objetivo de fazer o gol na trave do adversário. Muitas vezes algumas regras são decididas na hora, podendo variar de grupo para grupo. As crianças escolhem quando o jogo termina, sendo geralmente no tempo, 5 ou 10 minutos, ou no número de gols.

Pôde-se observar que nesta brincadeira também houve predominância do gênero masculino. 


\section{Dois Toques}

A brincadeira de dois toques se desenvolve com um número de crianças que varia geralmente de 4 até 7 . Utiliza-se geralmente uma bola de futebol, mas também há o uso de bolas de outras modalidades. O jogo é simples, o qual a regra principal consiste em que qualquer participante da brincadeira tem que passar a bola com os pés para o outro dando apenas um toque na bola. O jogador que der mais de um toque na bola, geralmente por acidente, está fora da brincadeira. O jogador vencedor é aquele que fica por último na brincadeira.

O gênero predominante nessa brincadeira é o masculino. Não foi observado meninas realizando a brincadeira.

\section{Bola de Gude}

A brincadeira de bola de gude é praticada geralmente entre 2 e 5 crianças. É feita na maioria das vezes na areia, onde podem existir alguns obstáculos naturais, fazendo com que a brincadeira fique mais interessante. Ela começa com as crianças desenhando um círculo ou um triângulo na areia, onde cada participante irá colocar um número igual de bolas de gude dentro deste espaço, por exemplo, são 5 participantes, cada um coloca dentro do triângulo 2 bolas de gude. Cada criança escolhe outra bola de gude, que será usada por ela para atingir as bolas de gude que estão dentro do espaço delimitado.

Para iniciar esta brincadeira, os participantes realizam um sorteio. A criança deve deslocar a bola que está em sua mão (realizando um movimento dos dedos) em direção as outras bolas que estão dentro do círculo ou triângulo desenhado no chão. Se ele conseguir atingir alguma bola, e esta sair das linhas do espaço demarcado, o jogador ganha a bola de gude para si, independente se a bola de gude seja dele ou de outro participante. Se a bolinha de outra criança for atingida, o jogador está fora da brincadeira. 
A brincadeira termina quando todos são eliminados da forma anteriormente descrita ou quando não há mais bolas de gude dentro do triângulo ou do círculo. O gênero mais predominante nessa brincadeira foi o masculino.

No presente estudo, outros tipos de brincadeiras individuais também foram observados, tais como:

\section{Skate e Patins}

As crianças andam com skate, alguns meninos faziam os bancos das praças de obstáculos para realizar pequenos saltos.

\section{Bicicleta}

Nesta brincadeira as crianças promovem um tipo de competição, estipulam um local e realizam uma corrida, o primeiro que chegar ao ponto marcado é o vencedor. Mas na maioria das vezes as crianças apenas pedalam sozinhas.

\section{Brincadeiras no playground}

São desenvolvidas nos parquinhos das praças, as crianças utilizam balanço, gangorra e o escorregador disponível nestes locais. Esses tipos de brincadeiras foram pouco observadas nas praças. Assim percebe-se a predominância das brincadeiras tradicionais.

Assim, no que diz respeito às brincadeiras que mais se repetiram, observou-se que o futebol com suas variações (dois toques) foi a que se mostrou mais presentes em todas as praças observadas. A brincadeira de pega-pega se repetiu em 4 das 5 praças observadas, 
taco ou rebatida em duas praças, esconde-esconde também em duas praças e outras brincadeiras (patins, skate, bicicleta e parquinhos) foram observadas apenas em 1 praça.

Nesta pesquisa, a procura pelas praças por parte das crianças como local para desenvolver suas brincadeiras e atividades de lazer foi boa, o número de crianças observadas utilizando os espaços das praças foi significativo, tendo em vista que, todas as praças onde se observou as brincadeiras, havia muitas crianças. Pode-se justificar essa procura, graças aos espaços adequados, ao índice de violência urbana ser relativamente baixo nos bairros visitados e a presença de rondas policiais constantes.

Em contrapartida aos nossos achados, os estudos realizados por Wenetz (2013) investigou dois bairros, Vila Jardim e Vila Ipiranga da cidade de São Paulo, a autora observou a ausência de crianças brincando nesses espaços. Ao investigar o problema, a autora entrevistou alguns pais e constatou que a principal causa da ausência de crianças brincando nas praças deve-se ao fato principalmente da violência urbana, o medo, a falta de confiança e a falta de espaços adequados, afirmando então, que a procura pelas praças pelas crianças em cidades grandes geralmente é menor que nas cidades menores, na maioria das vezes pelo medo da violência urbana.

Já na pesquisa realizada por Manfroi e Marinho (2014), observaram um alto índice de crianças desenvolvendo brincadeiras nas praças de Campo Grande-MS. Chegando à conclusão que as praças têm grande importância, principalmente quando localizadas próximo às residências, proporcionando experiência de cooperação entre as crianças, e também os adultos que acompanham as crianças até as praças. Sem contar que são espaços privilegiados para o encontro diário das crianças e dos adultos que residem próximo.

Ainda em conformidade com os nossos dados, Arruda e Müller (2010) realizou um estudo o qual verificou a incidência de crianças brincando nos espaços públicos na 
cidade de Maringá, no Paraná. Eles observaram que houve um número significativo de crianças com idade entre 7 e 13 anos realizando brincadeiras.

Nas nossas observações, percebeu-se que as crianças preferem brincar na praça a ficar em casa com jogos eletrônicos, assim um fato que foi percebido durante as observações é que nas praças nenhuma criança estava realizando algum tipo de brincadeira tecnológica (não usavam tablets nem celulares). Assim, observou-se que as brincadeiras tradicionais (que na atualidade são tidas como esquecidas) estão muito presente na vida das crianças que frequentam as praças da cidade de Patos-PB.

Nos estudos realizados por Fernandes et al. (2016) as crianças afirmaram que brincavam tanto de brincadeiras tradicionais quanto eletrônicas. Os autores entendem que, mesmo em uma época em que as crianças brasileiras têm acesso aos recursos eletrônicos que compõem o seu brincar, há também no seu cotidiano espaços para realizar atividades de jogos e brincadeiras populares.

Assim, conforme Cunha (2004) percebe-se que no universo da rua, as brincadeiras são vividas pelas crianças de forma constante e dinâmica, incluindo brincadeiras no quintal, na garagem ou terraço de casa. A rua, espaço tido como perdido para as brincadeiras e crianças em muitos bairros, conserva-se, nesse caso, como espaço de sociabilidade infantil. A predileção pelo brincar na rua demonstra o poder das brincadeiras tradicionais infantis perpetuadas pela apropriação do espaço coletivo e pela oralidade.

Os estudos de Cunha Júnior (1996) observaram a presença de jogos e brincadeiras que eram praticados há muitos anos e que se cogitava não estar mais presente entre as brincadeiras das crianças, devido a falta de transmissão pelas gerações anteriores e pela crescente urbanização. $\mathrm{O}$ autor registrou a realização das seguintes brincadeiras: Pula corda, amarelinha, carniça, bola de gude, taco, peteca e dominó. 
Conforme os dados obtidos durante as observações percebem-se que, com relação ao gênero, as brincadeiras como taco ou rebatida, travinha, dois toque e bola de gude eram realizadas sempre por meninos. Já as brincadeiras coletivas como pega-pega, pega-ajuda, esconde-esconde havia participação tanto de meninos quanto de meninas, não foi observado nenhuma brincadeira sendo realizada apenas por meninas. As crianças do sexo masculino foram as que mais se encontravam utilizando o espaço das praças para desenvolver as brincadeiras. As do sexo feminino também se mostraram presentes, mas em um número consideravelmente menor.

Para Brougère (1995) e Azevedo (2003), os estereótipos de gênero nos brinquedos estão relacionados ao dia-a-dia da sociedade patriarcalista, ou seja, o universo feminino tem conotação com a casa, a família, já o masculino está ligado aos carros, a luta, ao trabalho, e a liderança familiar. Nesse sentido Brougère (2004) afirma que a cultura lúdica é masculina por que a criança é menino, então, como menino age como tal, brinca apenas com outros meninos e ganha brinquedos destinados a meninos. A mesma coisa acontece com as meninas e ganha brinquedos relacionados a meninas. Isso é um reflexo da produção cultural ligada à construção da personalidade da criança decorrente da socialização.

Em estudos de Cordazzo e Vieira (2008) com relação ao gênero nas brincadeiras foi contatado, por meio de entrevistas, que os meninos são mais propensos a estereotipar mais as brincadeiras do que as meninas, principalmente as brincadeiras tidas por eles como masculinas. 


\section{Conclusão}

Notou-se que as brincadeiras mais tradicionais como o pega-pega, pega ajuda, esconde-esconde, travinha, dois toques e bola de gude se mostraram presentes em quase todas as praças, sendo assim pode-se concluir que de alguma forma as crianças estão mantendo a tradição de realizar brincadeiras tradicionais. Outro fato importante observado é a maioria das crianças que estão realizando brincadeiras nas praças são do gênero masculino.

Não foi observada também nenhuma criança fazendo uso de algum aparelho tecnológico em nenhuma praça, seja celular, tablet, notebook, etc. Sendo assim, entendese que as praças, para as crianças, são um espaço exclusivo para o desenvolvimento de brincadeiras tradicionais que vão muito além de jogos eletrônicos.

\section{REFERÊNCIAS}

ALVES, F. D.; SOMMERHALDER, A. O brincar: linguagem da infância, língua do infantil. Revista Motriz, Rio Claro, v. 12, n. 2, p. 125-132, mai/ago. 2006.

ARRUDA, F. M.; MÜLLER, V. R. Brincadeiras e espaços urbanos: um estudo da prática lúdica de crianças de diferentes classes sociais da cidade de Maringá-PR. Licere, v. 13, n. 4, dez. 2010.

AZEVEDO, T. M. C. Brinquedos e Gênero na educação infantil: um estudo do tipo etnográfico no estado do Rio de Janeiro. Tese (Doutorado em Psicologia e Educação) Faculdade de Educação, Universidade de São Paulo, São Paulo, 2003

BROUGÈRE, G. Brinquedo e cultura. São Paulo: Cortez, 1995.

BROUGÈRE, G. Brinquedos e companhia. São Paulo: Cortez, 2004.

CORDAZZO, S. T. D.; VIEIRA, M. L. Caracterização de brincadeiras de crianças em Idade Escolar. Psicologia: reflexão e crítica, v. 21, n. 3, p. 365-373, 2008.

CUNHA, C. T. Traços da Cultura Infantil: um estudo com grupos de crianças que brincam livremente. (Dissertação de mestrado) - Faculdade de Educação, Universidade Estadual de Campinas, Campinas, 2004.

CUNHA JÚNIOR, C. F. F. da. Jogos, brinquedos e brincadeiras: Investigando relações de gênero na experiência de crianças do Colégio Pedro II. Motrivivência, p. 236-245, dezembro, 1996. 
FERNANDES, B. P. F. et al. Entre o tradicional e o eletrônico: significados do brincar para crianças de uma escola pública de Piracicaba - SP. Revista Brasileira de Estudos de Lazer, v. 3, n. 2, p. 74-96, mai/ago. 2016.

HARADA, M. J.; PEDREIRA, M. L.; ANDREOTTI, J. T. Segurança com brinquedos de parques infantis: Uma introdução ao problema. Revista Latino-Americana de Enfermagem, v.11, n. 3, p. 383-386, 2003.

HARDER, I. C. F. Inventário quali-quantitativo da arborização e infra estrutura das praças da cidade de Vinhedo/SP. 2002. Dissertação (mestrado). Universidade de São Paulo, 2002.

KISHIMOTO, T. M. Bruner e a Brincadeira. In: KISHIMOTO, T. M. (Org.). O Brincar e suas Teorias. São Paulo, Pioneira Thomson Learning, 2002.

MACEDO, S. S.; ROBBA, F. Praças brasileiras. São Paulo: Edusp, 2002.

MANFROI, M. N.; MARINHO, A. A praça da poesia: entre histórias e brincadeiras. Licere, v. 17, n. 2, jun. 2014.

MARTINS JUNIOR, J. Como escrever trabalhos de conclusão de curso: instruções para planejar e montar, desenvolver, concluir, redigir e apresentar trabalhos monográficos e artigos. 9. ed. Petrópolis: Vozes, 2015.

MINAYO, M. C. S.; COSTA, A. P. Técnicas que fazem uso da palavra, do olhar e da empatia: pesquisa qualitativa em ação. Aveiro, Portugal: Editora Ludomedia, 2019.

OLIVEIRA, C. O ambiente urbano e a formação da criança. São Paulo: Aleph, 2004.

PIMENTEL, A. Brincadeiras de rua, convivência urbana e ecologia dos saberes. Revista Brasileira de Educação, v. 20, n. 62, p. 346, jul./set. 2015.

PINTO, L. M. S. M. Convivência no morro: caderno de atividades lúdicas de esporte e arte. Belo Horizonte: Lastro. 2005. 138p.

VIERO, Verônica Crestani; BARBOSA FILHO, Luiz Carlos. Praças públicas:origens, conceitos e funções. (artigo acadêmico). Santa Maria, 2009

WENETZ, I. As crianças ausentes na rua e nas praças. Civitas, v. 13, n. 2, p. 246-363, mai./ago., 2013.

\section{Endereço dos Autores:}

Alana Simões Bezerra

Rua Dr. José Genuíno, 1166 - Liberdade

Patos - PB - 58.703-060

Endereço Eletrônico: alanabezerra@ fiponline.edu.br

Diogo Peixoto Medeiros

Rua Santos Dumont, 01 - Liberdade

Patos - PB - 58.703-010

Endereço Eletrônico: dioggo0peixoto1@gmail.com 